\title{
THEORETICAL PREDICTIONS FOR ION COMPOSITION IN THE HIGH-LATITUDE WINTER F-REGION FOR SOLAR MINIMUM AND LOW MAGNETIC ACTIVITY
}

\author{
J. J. Sojka, W. J. Raitt, and R. W. Schunk
}

Center for Atmospheric and Space Sciences, Utah State University, Logan, Utah 84322

\begin{abstract}
We combined a simple plasma convection model with an ionospheric-atmospheric density model in order to study the ion composition in the high-latitude winter F-region at solar minimum for low geomagnetic activity. Our numerical study produced time-dependent, 3-dimensional, ion density distributions for the ions $\mathrm{NO}^{+}, \mathrm{O}_{2}^{+}, \mathrm{N}_{2}^{+}, \mathrm{O}^{+}, \mathrm{N}^{+}$, and $\mathrm{He}^{+}$. We covered the high-latitude ionosphere above $54^{\circ} \mathrm{N}$ magnetic latitude and at altitudes between 160 and $800 \mathrm{~km}$ for a time period of 1 complete day. From our study we found the following (1) The ion composition exhibits a significant variation with latitude, local time, altitude, and universal time. (2) The variations of the ion composition with latitude and local time are in good agreement with the Atmosphere Explorer measurements both quantitatively and qualitatively. (3) At times and at certain locations the molecular ion density can be comparable to the $\mathrm{O}^{+}$density at $300 \mathrm{~km}$, and at $200 \mathrm{~km}$ the $\mathrm{O}^{+}$density can be comparable to the molecular ion density. These results have important implications for the interpretation of incoherent scatter radar spectra obtained at high-latitudes. (4) Different ground-based observation sites should measure different diurnal variations in ion composition even if these sites are approximately at the same magnetic latitude owing to the UT response of the high-latitude ionosphere. (5) A satellite in a $300 \mathrm{~km}$ circular polar orbit should measure large orbit to orbit variations in both electron density and ion composition, again owing to the UT response of the polar ionosphere. (6) Erroneous conclusions can be drawn about ion density scale heights if the variations along the track of a satellite in a highly elliptical polar orbit are assumed to be only due to altitude variations.
\end{abstract}

\section{Introduction}

Over the last several years we have developed a theoretical model of the convecting high-latitude ionosphere in order to determine the extent to which various chemical and transport processes affect the ion composition and electron density in both the sunlit and the dark hemispheres (Banks et al., 1974; Schunk and Banks, 1975; Schunk et al., 1975, 1976; Schunk and Raitt, 1980). From these studies, as well as those by Knudsen (1974), Knudsen et al. (1977), Spiro et al. (1978), Watkins (1978), and Brinton et al. (1978), it is apparent that the high-latitude ionosphere can, by varying degrees, be influenced by solar EUV radiation, energetic particle precipitation, diffusion, thermospheric winds, electrodynamic drifts, polar wind escape, energy-dependent chemical reactions, and magnetic storm induced neutral composition changes.

In addition to the development of a high-latitude ionospheric-atmospheric model, we developed a simple model of high-latitude plasma convection (Sojka et al., 1979a, b, $1980 \mathrm{a}, \mathrm{b})$. Our convection model includes the offset between the geographic and geomagnetic poles, the tendency of plasma to corotate about the geographic pole, and a dawn/dusk magnetospheric electric field mapped to a circular region in the ionosphere about a center offset by $5^{\circ}$ in the antisunward direction from the magnetic pole. The radius of the circle corresponds to $17^{\circ}$ of latitude, and the electric potentials are aligned parallel to the noon/midnight meridian within the circular region. Equatorward of the circle the potential diminishes radially and varies inversely as the fourth power of sine magnetic colatitude.

Copyright 1981 by the American Geophysical Union.
Our convection model allows for asymmetries in the mapped magnetospheric electric field.

In order to determine the extent to which our simple convection model could account for specific observations, plasma convection patterns predicted by our model were compared to those observed concurrently at Chatanika, Alaska, and Millstone Hill, Massachusetts (Sojka et al., 1980a). These two incoherent scatter facilities operated over the same period of 4 days in June 1978 and provided data sets which were averaged to 24 hours in order to minimize the effects of individual substorms. The two radar facilities observed different diurnal patterns of horizontal plasma convection velocities even though the measurements covered approximately the same range of magnetic latitudes, a feature predicted by our convection model. In general, there was good agreement between our convection model and the different diurnal patterns observed at Chatanika and Millstone Hill.

Recently, we combined our convection and ionosphericatmospheric models in order to study the high-latitude F-region. Our new model produces time-dependent, 3-dimensional ion density distributions for the ions $\mathrm{NO}^{+}, \mathrm{O}_{2}{ }^{+}, \mathrm{N}_{2}^{+}, \mathrm{O}^{+}, \mathrm{N}^{+}$, and $\mathrm{He}^{+}$. We cover the high-latitude ionosphere above $54^{\circ} \mathrm{N}$ magnetic latitude and at altitudes between about 160 and $800 \mathrm{~km}$ for 1 complete day. The various physical processes entering into our model are shown schematically in Figure 1 . The neutral composition and thermospheric wind are inputs to our model as are the neutral and electron temperatures; these parameters vary over the polar cap. The EUV solar radiation spectrum and ion production owing to both auroral particle precipitation and resonantly scattered solar radiation are also inputs. In addition, our model requires the cross-tail magnetospheric potential, which is mapped down along dipole geomagnetic field lines. These parameters are used in the calculation of plasma convection, plasma diffusion, and photochemical processes, which in turn yield the ion density distributions. Further details of our new high-latitude ionospheric model are given by Sojka et al. (1980c).

In an initial application of our model, we studied the highlatitude winter F-region at solar minimum for low magnetic activity (Sojka et al., 1980c). The main result we obtained was that high-latitude ionospheric features, such as the 'main trough,' the 'ionization hole,' the 'tongue of ionization,' the 'aurorally produced ionization peaks,' and the 'universal time effects,' are a natural consequence of the competition between the various chemical and transport processes known to be operating in the high-latitude ionosphere. In this paper we expand upon this study and discuss the variations of the ion composition with magnetic latitude, local time, altitude, and universal time. The predictions for ion compositional variations are compared with the Atmosphere Explorer (AE-C) satellite data presented by Brinton et al. (1978). In addition, we discuss the effect of ion composition variations on the interpretation of incoherent scatter radar spectra, and we show how profiles of electron density obtained by in situ measurements from satellites with highly elliptical orbits can lead to erroneous conclusions about the plasma density altitude profiles.

\section{Morphology of Ion Composition}

\section{$\mathrm{O}^{+}$Density Morphology and Comparison With Data}

In Figure 2 the $\mathrm{O}^{+}$density is shown as a gray-scaled contour plot in a magnetic local time (MLT), magnetic latitude polar 


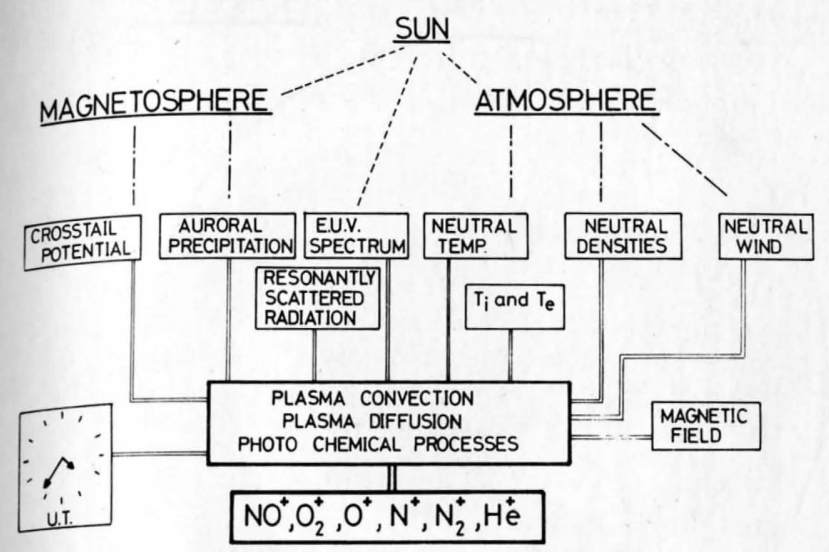

POLAR IONOSPHERE F-REGION

Fig. 1. Schematic illustration showing the various physical processes affecting the F-region polar ionosphere.

diagram. The MLT is shown as tick marks at 1 hour intervals, and magnetic latitude varies linearly from the $55^{\circ}$ circle shown to the magnetic pole at the center of each plot. In this figure the gray scale range was chosen to emphasize low density regions. The contour plots in Figure 2 clearly show a marked UT variation of the $\mathrm{O}^{+}$density distribution over the region poleward of $55^{\circ}$ latitude. These contour plots show the gross features of a mid-latitude (or main) ionization trough, a region of enhanced ionization in the vicinity of the auroral oval, and a high-latitude ionization hole around local dawn. However, the detailed characteristics of these features differ for the four UT times shown. For example, the depth and extent of the mid-latitude ionization trough differ considerably.

The $\mathrm{O}^{+}$density contours shown in Figure 2 can be compared with the Atmosphere Explorer (AE) satellite measurements of Brinton et al. (1978), who showed the variation of the minimum and maximum $\mathrm{O}^{+}$density at $300 \mathrm{~km}$ above the high-latitude region. Although these data correspond to roughly the same geophysical conditions that were adopted for our calculations, it is not possible to do a detailed comparison because the experimental data presented are incomplete and because no account was taken of the UT dependence of the high-latitude ionosphere when the data were plotted. Also, from the theoretical point of view, our model is uncertain with regard to the depth of the main trough because the depth is sensitive to nocturnal maintenance processes, which are not quantitatively well known. Nevertheless, the comparison of our model predictions with the gross features of the AE data produces some useful results. First, both the data and the model predictions display ionospheric features such as the main trough, the polar hole, and the enhanced ionization in the auroral oval. However, our $\mathrm{O}^{+}$ densities in the oval are generally larger than the measured values, indicating that our auroral production rates are probably too large. The location of the polar hole corresponds well with that observed; its size is strongly UT dependent and at about 0600 UT it extends into the noon polar cap sector. These latter two features are not present in the AE data owing to both the lack of UT data selection and a data gap over the polar cap. With regard to the depth of the polar hole, our model calculations produced $\mathrm{O}^{+}$densities as low as $2 \times 10^{2} \mathrm{~cm}^{-3}$, which are in good agreement with the observed densities, but our calculations also indicate a significant UT variation. As a final item we note that the maximum and minimum $\mathrm{O}^{+}$density plots display main troughs that are different in extent and form. Our model predicts a UT variation of the extent and form of the main trough, but it is not clear whether or not the variation presented by Brinton et al. (1978) is related to a UT effect, again owing to the omission of UT as a data selection criterion.
The $\mathrm{NO}^{+}$and $\mathrm{O}_{2}^{+}$morphology

Figure 3 shows the $\mathrm{NO}^{+}$density at $300 \mathrm{~km}$ for the same four UT's as used in Figure 2. The range of the gray scale key has been changed to highlight the lower densities found for the molecular ions. A pair of oval-shaped curves have been included in each figure to show the auroral oval location used in our model. The oval from 1200 to 0400 MLT is 'active' in that auroral precipitation was present, while from 0400 to 1200 MLT no precipitation was present. The two regions of active and nonactive oval are clearly seen in Figure 3; each panel shows an identical, UT independent, active oval sector. The additional higher density patches associated with this active oval are the result of the magnetic field tubes of plasma entering and leaving the oval.

Outside the active oval region the $\mathrm{NO}^{+}$density shows a marked UT dependence. This is seen most easily by comparing the extreme density regions. The lowest densities, less than $10^{2}$ $\mathrm{cm}^{-3}$, being the darkest shade and the highest densities, greater than $2.5 \times 10^{3} \mathrm{~cm}^{-3}$, appearing as white. In the polar cap a region of low density is located adjacent to the evening sector poleward edge of the oval, and a region of high density is found in the late morning-noon sector. A region of low $\mathrm{NO}^{+}$density is also found in the dawn sector, where the field tubes of plasma have left the active oval and are convecting sunward. This low $\mathrm{NO}^{+}$density region results because $\mathrm{NO}^{+}$production owing to particle precipitation disappears as the plasma leaves the active oval, but the $\mathrm{O}^{+}$density and, hence, $\mathrm{NO}^{+}$recombination rate remain high owing to photoionization. Finally, it should be noted that another low $\mathrm{NO}^{+}$density region exists equatorward of the nocturnal auroral oval in the region of the main trough.

The third most abundant ion at $300 \mathrm{~km}$ is $\mathrm{O}_{2}{ }^{+}$; Figure 4 shows its density morphology in a format identical with that of Figure 3. Again the oval is apparent with its 'fine structure' patches of high density. Most of the region extending from 0600 to 1800 MLT has a density in one contour interval which ranges from $10^{2}$ to $5 \times 10^{2} \mathrm{~cm}^{-3}$. In the polar cap a large UT dependent region of low density is located adjacent to the morning sector, poleward edge of the oval. Equatorward of the oval in the evening and morning sectors is a deep $\mathrm{O}_{2}{ }^{+}$trough. This trough extends to about $1000 \mathrm{MLT}$ at $0800 \mathrm{UT}$ and recedes to 0600 MLT at 2000 UT.

\section{Comparison Between $\mathrm{NO}^{+}$and $\mathrm{O}_{2}^{+}$Densities and Observations}

The comparison of the $\mathrm{NO}^{+}$and $\mathrm{O}_{2}^{+}$density distributions shows that $\mathrm{NO}^{+}$is the dominant molecular ion in the 'active' oval; most of the 0700-1700 MLT sector and the morning sector mid-latitude trough. For the $0200 \mathrm{hr}$ and $2000 \mathrm{UT}$ plots, $\mathrm{O}_{2}{ }^{+}$is dominant in the dusk mid-latitude trough region. There are two additional regions where $\mathrm{O}_{2}{ }^{+}$dominates (i.e., in the polar cap adjacent to the evening sector poleward oval boundary and in the nonactive oval from 0500 to 0800 MLT). Table 1 summarizes these regions of the polar ionosphere at $300 \mathrm{~km}$, indicating the dominant molecular ion. This table also includes the general results of the $\mathrm{AE}$ observations presented by Brinton et al. (1978), who show the regions in the polar ionosphere at 300 $\mathrm{km}$ where a given molecular ion dominates. In general there is a very favorable comparison between our model calculations and the AE observations; the one exception, region 3 in Table 1, will be discussed later. Not only is the dominant molecular ion in five of the six regions in agreement with Brinton et al. (1978), but the spatial extents of the various regions also show marked similarities. For example, the dusk mid-latitude trough region, where either $\mathrm{NO}^{+}$or $\mathrm{O}_{2}^{+}$can dominate, is significantly larger than the two regions where $\mathrm{O}_{2}^{+}$dominates, that is, in the polar cap and morning sector nonactive oval region.

A detailed comparison between the calculated and observed molecular ion densities is difficult because of the lack of UT sorting of the experimental data and the absence of data from 


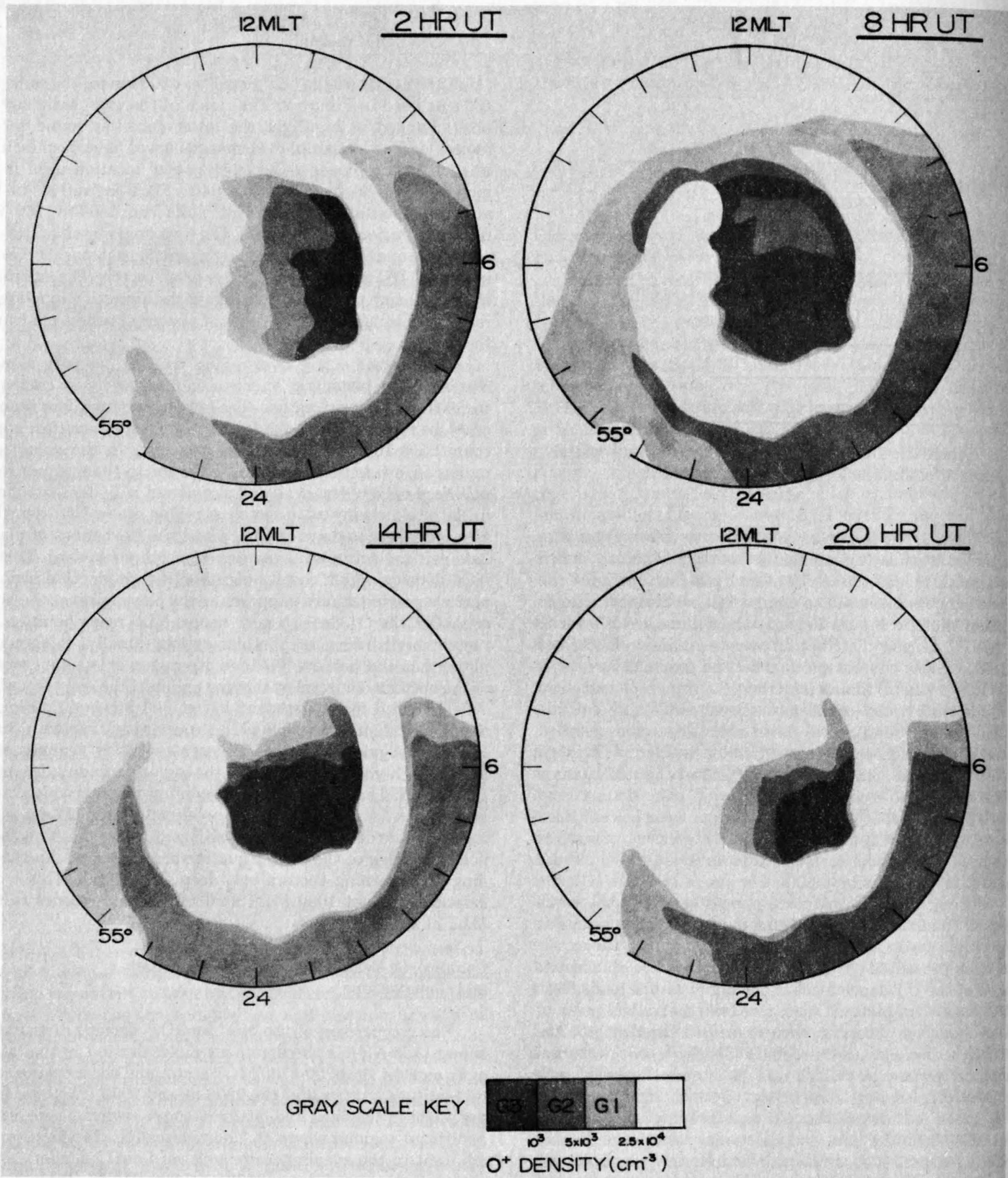

Fig. 2. $\mathrm{O}^{+}$density contours at $300 \mathrm{~km}$ in the magnetic quasi-inertial frame for four equally spaced universal times. The contour range was chosen to highlight the low density regions. Magnetic latitude varies linearly from the center of each plot.

certain key regions. Nevertheless, a quantitative comparison between calculated and observed densities is useful. For $\mathrm{NO}^{+}, \mathrm{a}$ region of interest is the polar cap between 0600 and 1200 MLT, where densities greater than $2.5 \times 10^{3} \mathrm{~cm}^{-3}$ were calculated for certain UT's; at other UT's the calculated $\mathrm{NO}^{+}$densities fall between $5 \times 10^{2}$ and $2.5 \times 10^{3} \mathrm{~cm}^{-3}$ in this polar cap region. This variation is clearly evident in the $\mathrm{AE}$ data set presented by Brinton et al. (1978, Figure 4, panels a and b). The $\mathrm{NO}^{+}$densities in the polar hole region also agree well with those observed, with the lowest values falling below $10^{2} \mathrm{~cm}^{-3}$. The $\mathrm{O}_{2}^{+}$densities in Figure 4 are predominantly in the $10^{2}$ to $5 \times 10^{2} \mathrm{~cm}^{-3}$ range, which again are in the same range as that observed.
As noted earlier there is a discrepancy between our model and the observations in region 3 given in Table 1 , where the calculations show $\mathrm{NO}^{+}$dominant and the observations show $\mathrm{O}_{2}^{+}$to be the dominant molecular ion. This region is the late evening to early morning mid-latitude trough, a region where plasma densities of the order of $10^{3} \mathrm{~cm}^{-3}$ are maintained by nocturnal processes. In Sojka et al. (1980c) we studied the extent to which different nocturnal maintenance processes could affect our results, including production due to resonantly scattered solar radiation, production due to an enhanced level of resonantly scattered solar radiation, production due to a small flux of precipitating particles, and a neutral wind induced upward 


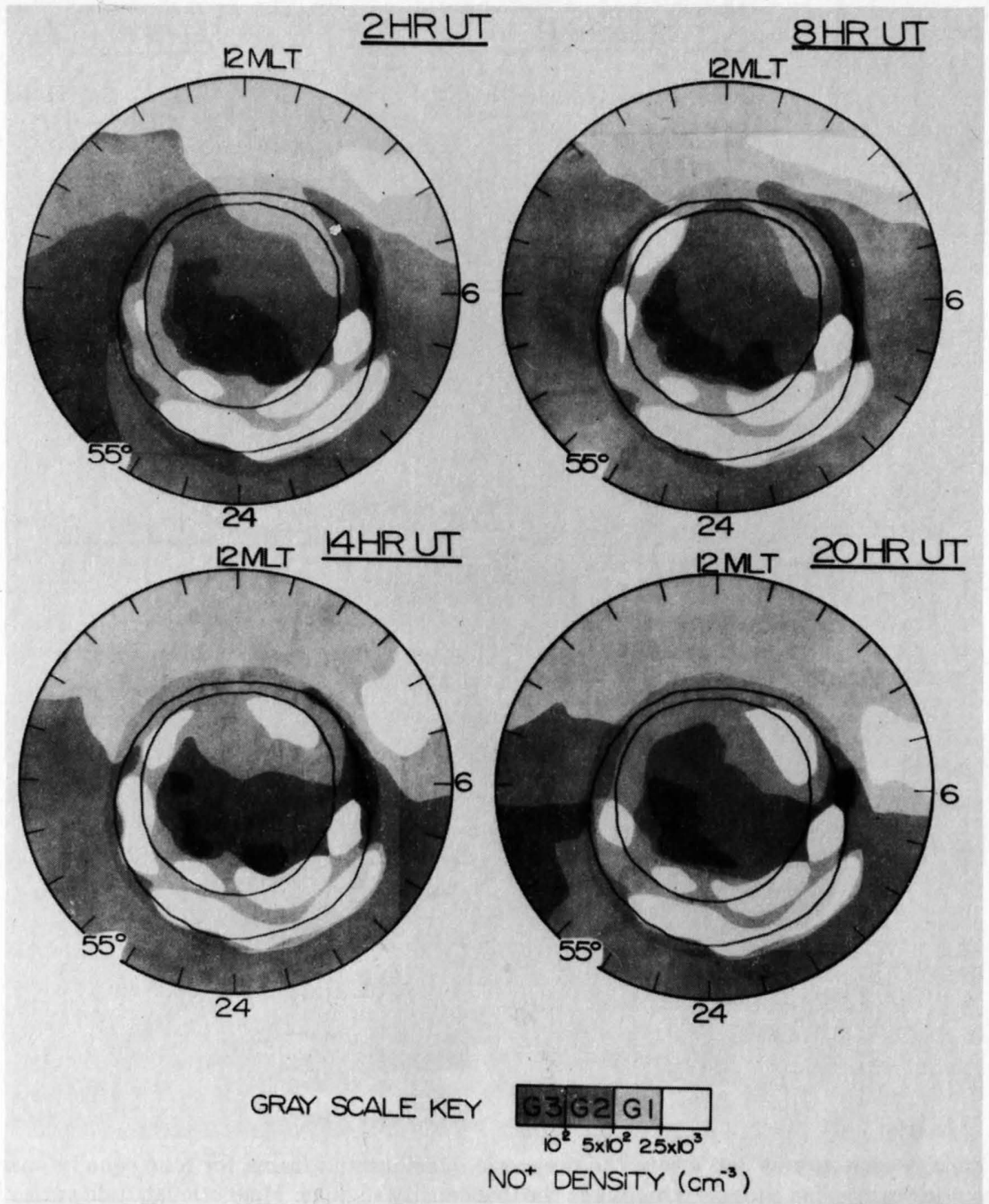

Fig. 3. $\mathrm{NO}^{+}$density contours at $300 \mathrm{~km}$ in the magnetic quasi-inertial frame for four equally spaced universal times. The contour range was chosen to highlight the low density regions. Magnetic latitude varies linearly from the center of each plot.

ionization drift. We found that any one of the latter three processes is capable of maintaining the electron density at $300 \mathrm{~km}$ in the mid-latitude trough at a level greater than $10^{3} \mathrm{~cm}^{-3}$, as required by satellite measurements. To simulate the effect of these nocturnal maintenance processes, we adopted an enhanced resonantly scattered radiation production rate for the midlatitude trough region. While this choice provided an adequate description of the major ion $\left(\mathrm{O}^{+}\right)$behavior, it appears that the mechanism results in an erroneous prediction for the minor ion composition.

We repeated our study of the effect that nocturnal maintenance processes have on the mid-latitude trough, and we found that of the four mechanisms considered only a neutral wind induced upward ionization drift is capable of producing both the electron density and the ion composition that was measured by Brinton et al. (1978) at $300 \mathrm{~km}$. For our study we adopted the thermospheric wind pattern used by Murphy et al. (1976); this wind is a function of both local time and latitude. With allowance for the effects of this thermospheric wind, $\mathrm{O}^{+}{ }_{2}$ becomes the dominant molecular ion at $300 \mathrm{~km}$ in the midlatitude trough, in agreement with the measurements (see Table 1 , region 3). At higher latitudes the effect of the thermospheric wind is much smaller owing to the larger geomagnetic field dip angles.

\section{Mean Ion Mass}

In addition to comparing the molecular ions with each other and with observations it is possible to compare them with the major ion $\mathrm{O}^{+}$. Comparing Figures 2, 3, and 4 at each of the four UT's is rather difficult; however, there are regions where the $\mathrm{O}^{+}$ density is below $10^{3} \mathrm{~cm}^{-3}$ and the molecular ions are not below $10^{2} \mathrm{~cm}^{-3}$ (the lowest density shade). One such region is in the polar cap in the 0800 UT period. This suggests that, at times, the molecular ion density can be comparable to the $\mathrm{O}^{+}$density at an altitude as high as $300 \mathrm{~km}$.

A single parameter that can be used to study the ion composition is the mean ion mass. At altitudes below $400 \mathrm{~km}$ this parameter is useful for representing the composition because the molecular ions $\mathrm{NO}^{+}(30 \mathrm{amu})$ and $\mathrm{O}_{2}^{+}(32 \mathrm{amu})$ are approximately twice as heavy as $\mathrm{O}^{+}(16 \mathrm{amu})$; therefore, even relatively small concentrations of molecular ions have an appreciable effect on the mean ion mass. For example, $80 \% \mathrm{O}^{+}$and $20 \% \mathrm{O}_{2}{ }^{+}$ yields a mean ion mass of $19.2 \mathrm{amu}$.

Figure 5 shows the mean ion mass as a function of MLT and magnetic latitude at three altitudes for two UT's. The mean ion mass is shown as contours labeled in atomic mass units (amu). The three altitudes, 200, 260, and $300 \mathrm{~km}$ were selected to cover the altitude region where the dominant ion changes from a 


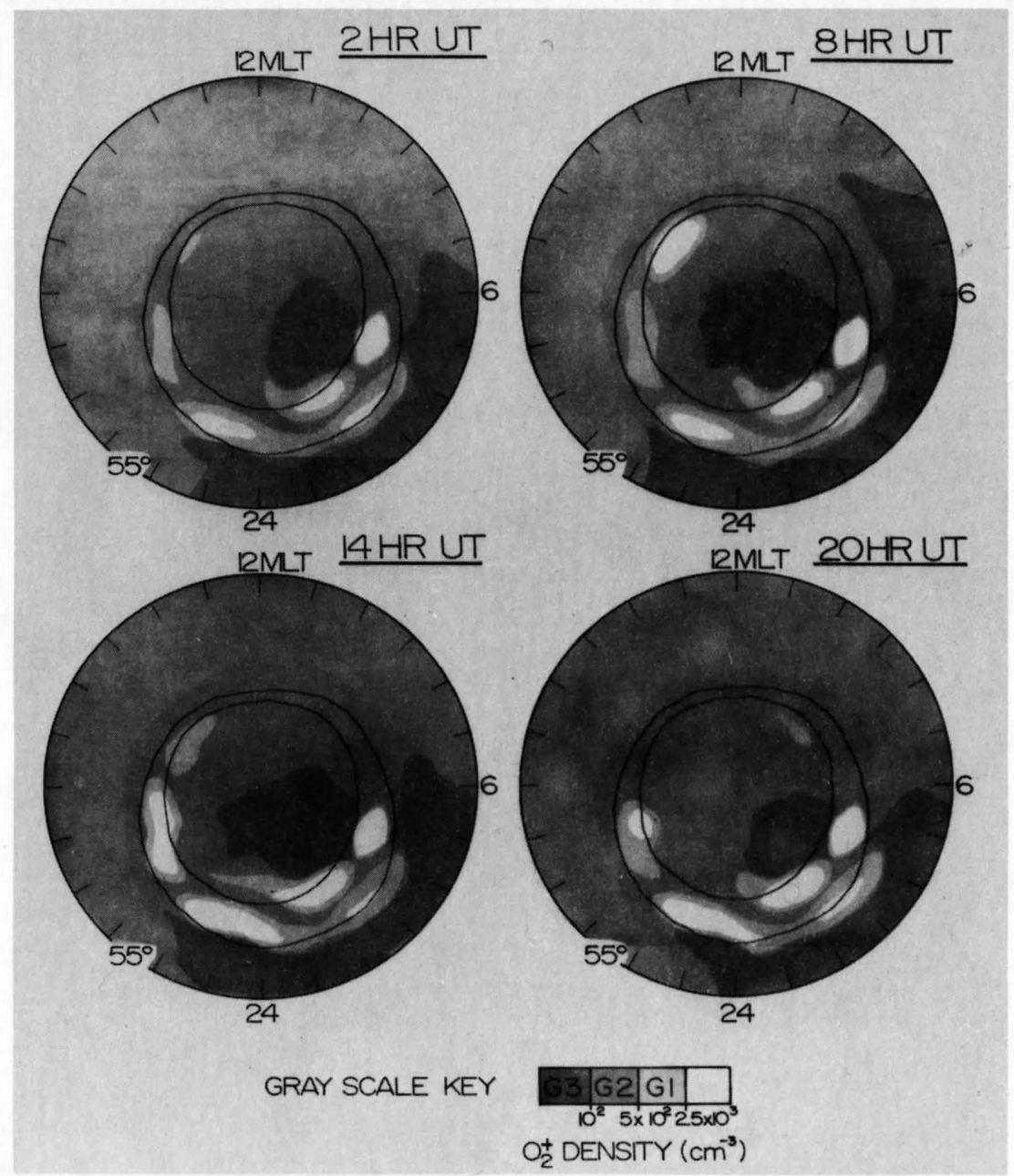

Fig. 4. $\mathrm{O}_{2}{ }^{+}$density contours at $300 \mathrm{~km}$ in the magnetic quasi-inertial frame for four equally spaced universal times. The contour range was chosen to highlight the low density regions. Magnetic latitude varies linearly from the center of each plot.

molecular to an atomic ion. At each altitude the same two UT's, 0800 and 2000 , are shown. At $300 \mathrm{~km}$ a mean ion mass less than $17 \mathrm{amu}$ is dominant over most of the polar ionosphere; this corresponds to a composition of more than $95 \% \mathrm{O}^{+}$. There are, however, regions in the polar cap where up to $30 \%$ of the composition is molecular ions. In a small region at the dawn side of the polar cap is a mean mass greater than $24 \mathrm{amu}$, which corresponds to about a $50 \%$ molecular ion composition. It should also be noted that there is a marked UT variation in composi-

TABLE 1. Calculated and Observed Regional Variation of the Dominant Molecular Ion at an Altitude of $300 \mathrm{~km}$

\begin{tabular}{|c|c|c|}
\hline Description of Region & $\begin{array}{c}\text { Calculated } \\
\text { (Present Study) }\end{array}$ & $\begin{array}{c}\text { Observed } \\
\text { (Brinton et al., 1978) }\end{array}$ \\
\hline Active auroral oval & $\mathrm{NO}^{+}$ & $\mathrm{NO}^{+}$ \\
\hline 0700-1700 MLT & $\mathrm{NO}^{+}$ & $\begin{array}{l}\mathrm{NO}^{+} \\
\text {(some data gaps) }\end{array}$ \\
\hline $\begin{array}{l}\text { Morning sector mid- } \\
\text { latitude trough }\end{array}$ & $\mathrm{NO}^{+}$ & $\mathrm{O}_{2}^{+}$ \\
\hline $\begin{array}{l}\text { Dusk sector mid- } \\
\text { latitude trough }\end{array}$ & $\begin{array}{l}\text { either } \mathrm{NO}^{+} \text {or } \mathrm{O}_{2}^{+} \text {, } \\
\text { [UT dependent] }\end{array}$ & either $\mathrm{NO}^{+}$or $\mathrm{O}_{2}^{+}$ \\
\hline $\begin{array}{l}\text { Evening sector polar } \\
\text { cap adjacent to } \\
\text { auroral oval }\end{array}$ & $\mathrm{O}_{2}^{+}$ & $\mathrm{O}_{2}^{+}$ \\
\hline $\begin{array}{l}\text { Dawn sector, non- } \\
\text { active auroral oval }\end{array}$ & $\mathrm{O}_{2}^{+}$ & $\mathrm{O}_{2}^{+}$ \\
\hline
\end{tabular}

tion in the polar cap and that the local time extent of the morning sector mid-latitude trough also shows a UT dependence.

The $260 \mathrm{~km}$ mean ion mass shown in Figure 5 shows a significantly larger region of $50 \%$ molecular ion composition, but this region, like that at $300 \mathrm{~km}$, is in the polar cap. In the morning sector mid-latitude trough the composition has a molecular ion content in excess of $30 \%$. At $200 \mathrm{~km}$ the ion composition has a predominantly molecular ion component, greater than $24 \mathrm{amu}$, at $0800 \mathrm{UT}$, while at $2000 \mathrm{UT}$, comparably sized regions of greater than and less than 24 amu are present. The active oval region is highlighted by the low atomic mass contours, indicating $\mathrm{O}^{+}$is major even at this low altitude. For both 260 and $200 \mathrm{~km}$ a UT dependence in the composition is clearly evident.

\section{Predicted Composition Variations at Selected Ground-Based Observation Sites}

The F-region ionosphere can be probed by using a variety of ground-based techniques to yield information on parameters such as density, temperature, and plasma drift velocity. One such technique is the incoherent scatter radar, which has been widely used to probe the ionosphere from low to high latitudes. In a previous study we compared the predictions of our plasma convection model with incoherent scatter measurements at Chatanika, Alaska, and Millstone Hill, Massachusetts (Sojka et al., 1980a). Encouraged by the favorable comparison between 

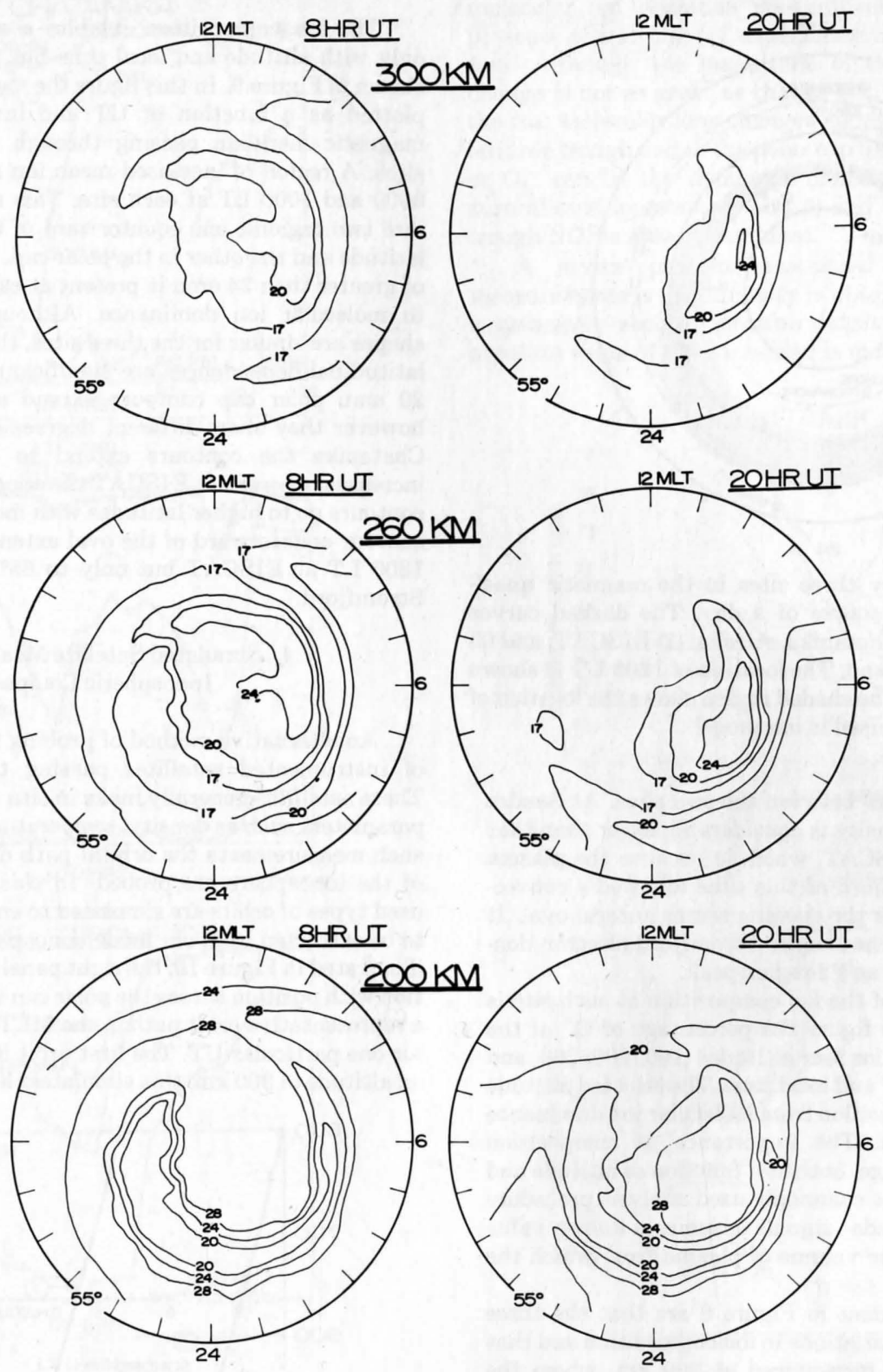

Fig. 5. Contours of mean ion mass at two universal times for each of three altitudes. The reference frame is the same as in the previous figures. The mean ion mass is in atomic mass units.

theory and measurement, we then used our convection model to predict plasma drift velocities expected at other ground-based sites located in the high latitude region, i.e., Tromso (EISCAT), Norway, and Sondre Stromfjord, Greenland (Sojka et al., 1979b). The former site is under development, while the latter site has been suggested as a location for a new incoherent scatter radar facility to probe the polar cap ionosphere. Since ion composition plays an important role in the interpretation of incoherent scatter radar spectra, we selected three of these ground-based sites and studied the variation of ion composition in a manner that is relevant to the measurement made by incoherent scatter radars.

The first two sites are Chatanika (geographic latitude, $65^{\circ}$, and longitude, $145^{\circ} \mathrm{W}$ ) and Tromso (geographic latitude, $70^{\circ}$, and longitude, $18^{\circ} \mathrm{E}$ ). These two sites are approximately at the same magnetic latitude, $65^{\circ}$ and $66^{\circ}$, respectively; however, their longitudes differ by about $180^{\circ}$. Hence, these two sites can be regarded as being at the same magnetic latitude, but they have a half-day UT phase difference. Figure 6 shows the paths traced out by these two sites in a magnetic local time, magnetic latitude coordinate system. The half-day phase lag is indicated by arrows, showing the locations of the two sites at 1200 UT. Also shown in Figure 6 is the path traced out by the third ground-based site, Sondre Stromfjord (geographic latitude, $67^{\circ}$, and longitude, $51^{\circ} \mathrm{W}$ ). This site, which lies inside the polar cap, is poleward of the oval and complements the other two which lie equatorward of the oval.

Figure 7 shows the effect on the total ion density of different UT phase angles and different locations relative to the oval for the three observation sites. Each profile corresponds to the respective site being located on the dawn-dusk MLT meridian, as shown by the dots labeled 1, 2, and 3 in Figure 6 . The Chatanika and EISCAT profiles are at 1800 MLT, while the Sondre Stromfjord profile is at 0600 MLT. At these times, both Chatanika and EISCAT are equatorward of the auroral oval, while Sondre Stromfjord is in the polar cap. It is apparent that there is an order of magnitude difference between the Chatanika and EISCAT density profiles, which is a consequence of the 


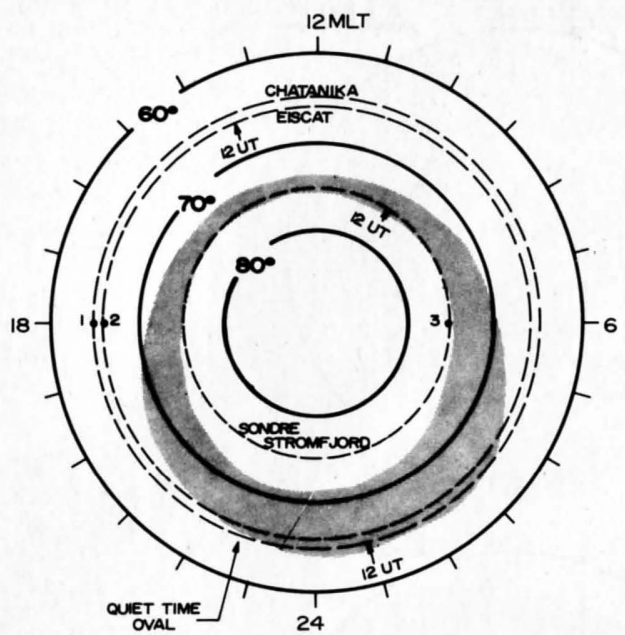

Fig. 6. Path traced out by three sites in the magnetic quasiinertial frame during the course of a day. The dashed curves represent the paths of (1) Chatanika, Alaska; (2) EISCAT; and (3) Sondre Stromfjord, Greenland. The location of 1200 UT is shown by an arrow for each site. The shaded region shows the location of the quiet-time auroral oval used in our model.

half-day UT phase difference between the two sites. At Sondre Stromfjord the electron density is considerably lower than that at either Chatanika or EISCAT, which is because the plasma observed at Sondre Stromfjord at this time followed a convection path that did not enter the evening sector auroral oval. It should also be noted that the Sondre Stromfjord electron density profile does not exhibit an F2-region peak.

The diurnal variation of the ion composition at each site is shown in Figure 8. In this figure the percentage of $\mathrm{O}^{+}$of the total ion density is plotted for four altitudes $(160,200,260$, and $300 \mathrm{~km}$ ) as a function of UT and local time. The selected altitude range encompasses the transition from molecular ion dominance to atomic ion dominance. The importance of composition changes in this altitude range, both as a function of altitude and time, lies in the fact that the commonly used analysis procedure of the incoherent scatter radar signals assumes a known value of the mean ion mass in the volume of plasma from which the signal is scattered.

The features most evident in Figure 8 are that the three sites see different diurnal variations in ion composition and that these variations are most pronounced at $200 \mathrm{~km}$, where the percentage $\mathrm{O}^{+}$can range from 20 to $80 \%$ during the day. At Sondre Stromfjord the percentage $\mathrm{O}^{+}$shows one broad maximum which occurs in the late afternoon. This modulation is also apparent at 260 and $300 \mathrm{~km}$. Chatanika shows two peaks in the percentage $\mathrm{O}^{+}$at $200 \mathrm{~km}$, one centered about $0300 \mathrm{LT}$, corresponding to Chatanika being in the oval, and the second about $1300 \mathrm{LT}$. At 260 and $300 \mathrm{~km}$ the modulation at Chatanika is relatively small compared to Sondre-Stromfjord or EISCAT; at these two altitudes $\mathrm{O}^{+}$is the major ion by a large margin at Chatanika. The EISCAT diurnal variation of percentage $\mathrm{O}^{+}$at $200 \mathrm{~km}$ shows three peaks, one in the midnight sector oval and the other two on either side of noon. This triple modulation highlights the complexity introduced by the UT dependent convection in the geographic frame or alternatively, the UT dependent EUV terminator position in the magnetic frame. The modulation at 260 and $300 \mathrm{~km}$ is significantly greater than that predicted for Chatanika, and the deepest modulation in percentage $\mathrm{O}^{+}$at these altitudes occurs at different local times for these two sites. At Chatanika the lowest percentage $\mathrm{O}^{+}$occurs prior to entry into the oval at $2300 \mathrm{LT}$, and at EISCAT the minimum is at $0400 \mathrm{LT}$, although a secondary minimum of comparable depth to that at Chatanika is present prior to entry into the oval.
The ion composition exhibits a significant variation not only with altitude and local time but with latitude as well, as shown in Figure 9. In this figure the mean ion mass at $260 \mathrm{~km}$ is plotted as a function of UT and invariant latitude for the magnetic meridian passing through the three ground-based sites. A region of increased mean ion mass is present between 0000 and $1000 \mathrm{LT}$ at each site. This region is further divided into two regions, one equatorward of the oval at $65^{\circ}$ invariant latitude and the other in the polar cap. In the polar cap a region of greater than 24 amu is present at each site; this corresponds to molecular ion dominance. Although the general contour shapes are similar for the three sites, the detailed local time and latitudinal dependences are significantly different. The 17 and $20 \mathrm{amu}$ polar cap contours extend above a latitude of $81^{\circ}$, however they show different degrees of skewing with UT. At Chatanika the contours extend to lower latitudes as UT increases, whereas at EISCAT the opposite trend is present; the contours go to higher latitudes with increasing UT. The $17 \mathrm{amu}$ contour equatorward of the oval extends to a latitude of $69^{\circ}$ at $1800 \mathrm{LT}$ at EISCAT but only to $65^{\circ}$ at $2300 \mathrm{LT}$ for Sondre Stromfjord.

\section{Simulated Satellite Measurements of Ionospheric Composition}

An alternative method of probing the ionosphere is the use of instrumented satellites passing through the ionosphere. These satellites generally make in situ measurements of plasma parameters such as density, temperature, and drift velocity. For such measurements the orbital path determines which regions of the ionosphere are probed. In this section, two commonly used types of orbits are simulated to enable satellite predictions to be extracted from our model ionosphere. These two orbits are illustrated in Figure 10; the right panel shows the altitude variation with position across the polar cap while the left panel shows a representative orbit path in the MLT-magnetic latitude frame for one particular UT. The first orbit is a circular polar orbit at an altitude of $300 \mathrm{~km}$; this simulates the AE-C orbit. The second

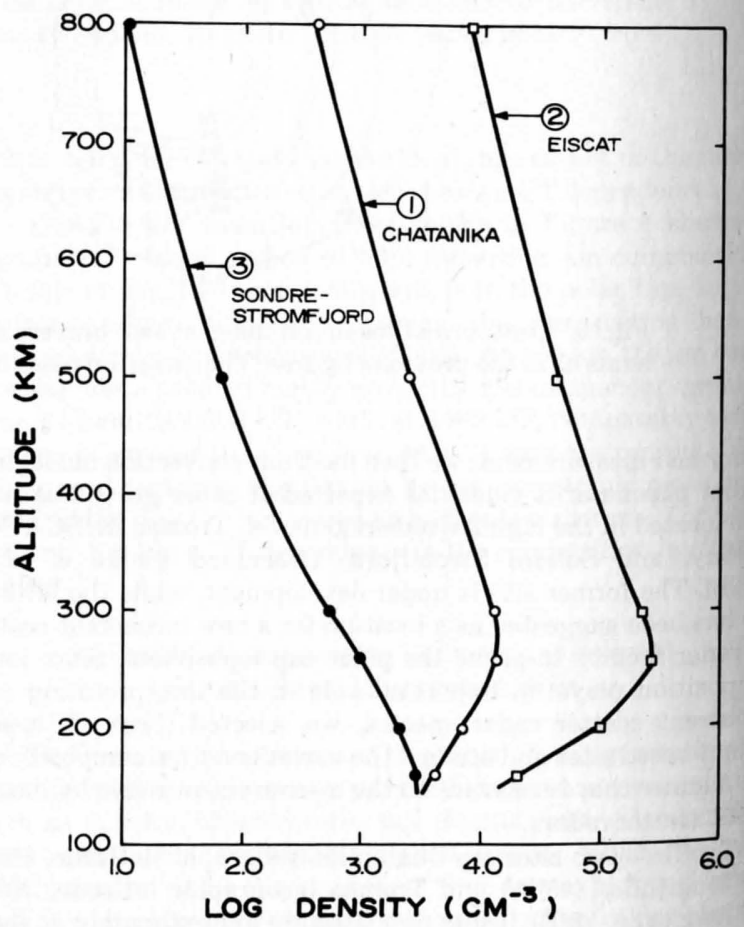

Fig. 7. Altitude profiles of electron density at the three points labeled 1, 2, and 3 in Figure 6. These profiles show the lowest electron density observed by each site in the dawn-dusk magnetic meridian. 

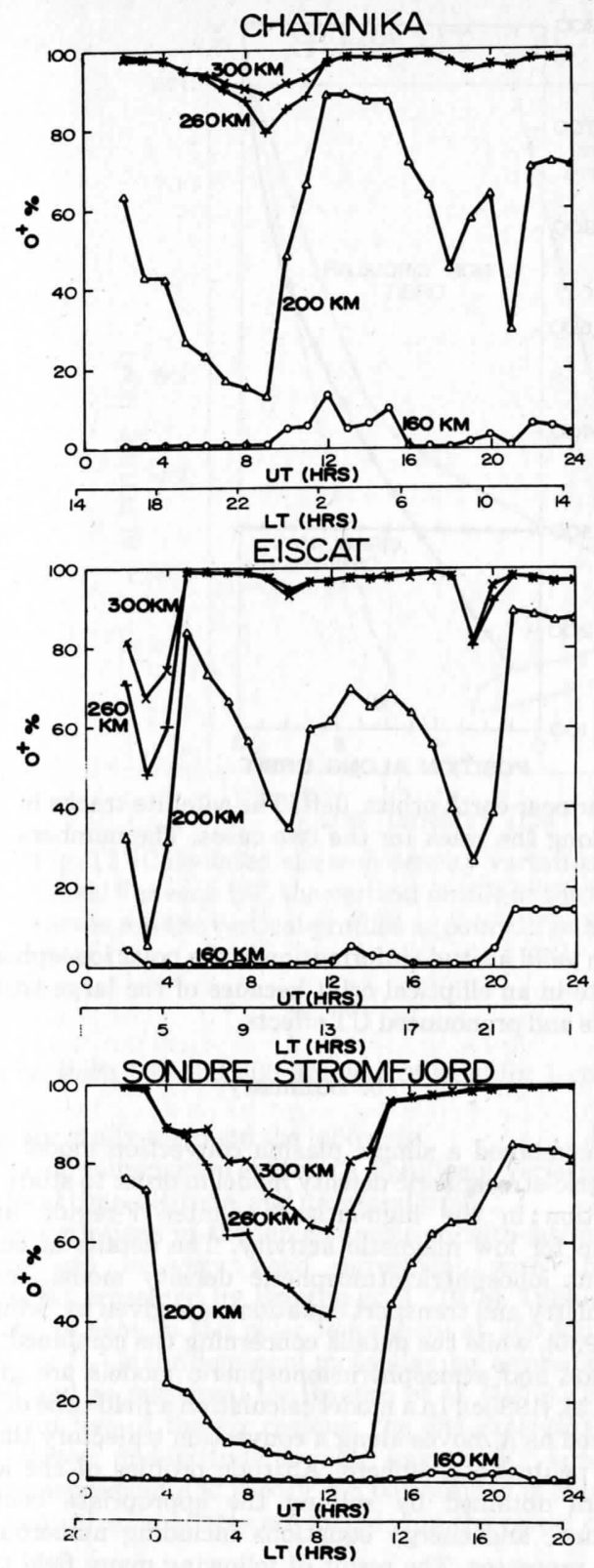

Fig. 8. Percentage of $\mathrm{O}^{+}$as a function of universal time for 1 day at four altitudes for each of the three sites shown in Figure 6. Also shown is the local solar time variation for each site.

orbit is highly elliptical to simulate the AE-D orbit; as it crosses the polar ionosphere its altitude changes from 160 to $800 \mathrm{~km}$.

Figure 11 shows the ion composition that would be obtained from an in situ measurement along a circular satellite track through our model ionosphere. The four UT's correspond to four passes through the ionosphere during the course of a day. The location of the satellite is indicated by orbital position numbers; these numbers correspond to those shown in Figure 10. For all four traversals through our model ionosphere, $\mathrm{O}^{+}$is the dominant ion, and therefore, the main regions of ionization can be readily identified from the $\mathrm{O}^{+}$density variation. The UT independent high density region between positions 4 and 6 corresponds to the oval ionization; outside this narrow latitudinal region the $\mathrm{O}^{+}$density shows a highly UT dependent character. In the dusk mid-latitude trough a factor of 10 variation is found, whereas a factor of 100 change in the $\mathrm{O}^{+}$density is present in the polar cap (position 8 ). The respective UT change in the molecular ion densities is significantly less, indicating the presence of a strong UT dependence in the overall ion composition. Although the magnitude of the molecular ion density change is not as great as that of $\mathrm{O}^{+}$, the relative abundance of the two molecular ions changes significantly. In the dusk midlatitude trough and in the polar cap (positions 6 to 8) either $\mathrm{NO}^{+}$ or $\mathrm{O}_{2}^{+}$can be the dominant molecular ion. However, in the auroral oval (positions 4 and 5) and in the dawn mid-latitude trough $\mathrm{NO}^{+}$is always dominant.

A severe problem associated with in situ satellite measurements is the difficulty in obtaining altitude gradients of a parameter such as electron density at the point where the absolute value of the parameter is measured. The importance of
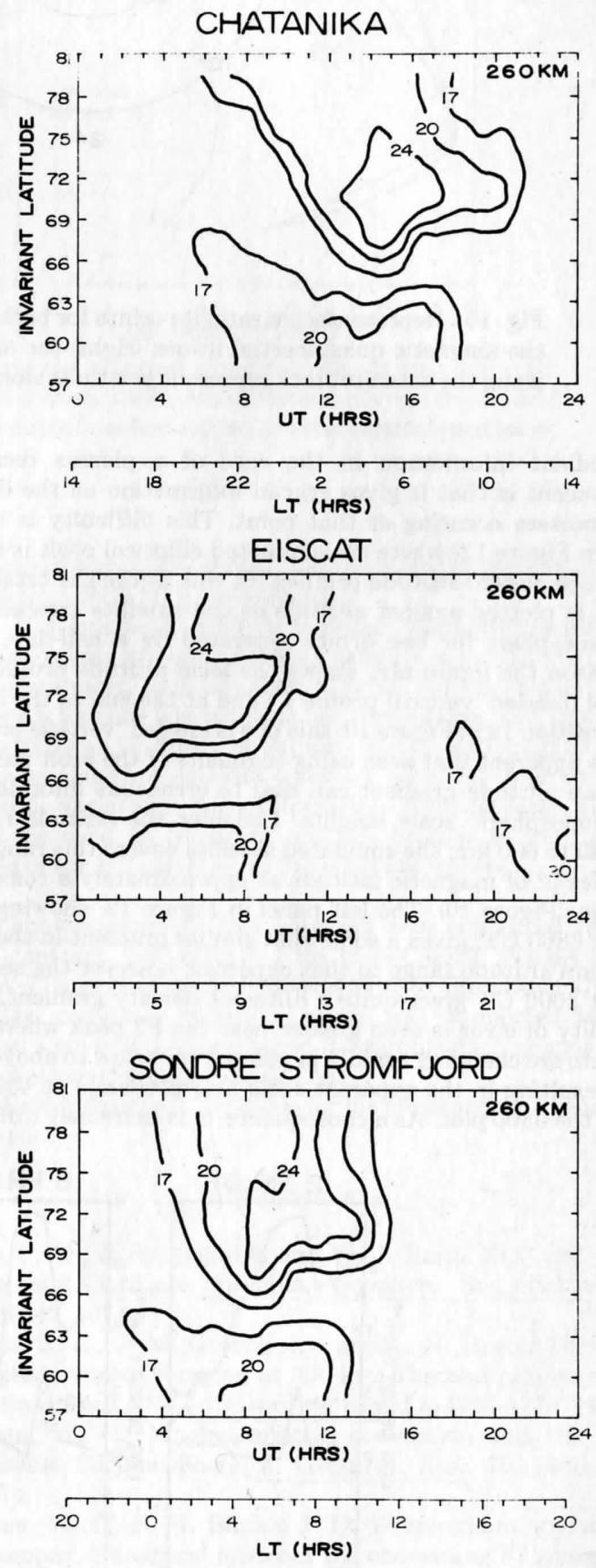

Fig. 9. Contours of mean ion mass as a function of invariant latitude and universal time at $260 \mathrm{~km}$ for each of the three sites shown in Figure 6. Also shown is the local solar time variation for each site. 

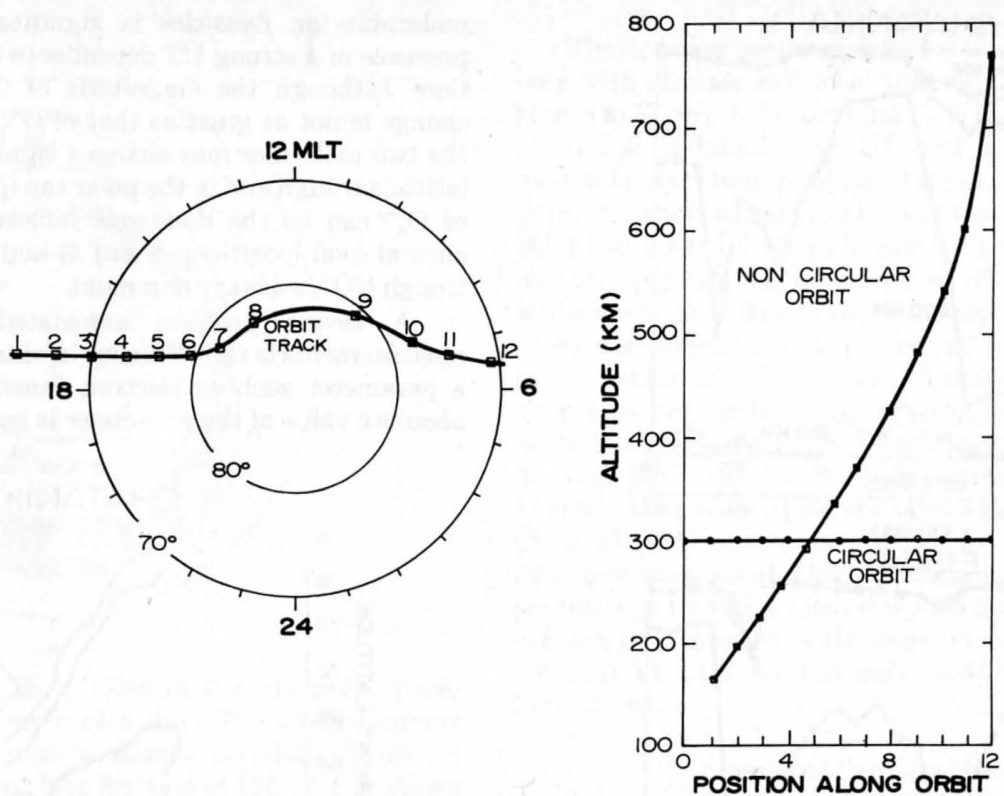

Fig. 10. Representative satellite orbits for both elliptic and circular near-earth orbits. (left) The satellite tracks in the magnetic quasi-inertial frame; (right) the altitude variation along the track for the two cases. The numbers along the satellite track represent positions along the orbit.

the gradient information in the case of a plasma density measurement is that it gives crucial information on the diffusion processes occuring at that point. This difficulty is illustrated in Figure 12, where the simulated elliptical orbit is used to produce pseudo-altitude profiles. In this figure the total ion density is plotted against altitude as the satellite crosses the polar ionosphere for two orbits separated by a half-day. For comparison the figure also shows the local altitude profiles in the oval (labeled 'vertical profile 1') and at the end of the orbit path (position 12 in Figure 10; this one is labeled 'verticle profile 2 '). It is apparent that even using segments of the orbit path to obtain an altitude gradient can lead to erroneous information about ionospheric scale heights. Consider the altitude range from 540 to $600 \mathrm{~km}$; the simulated satellite covers this range as it crosses $3^{\circ}$ of magnetic latitude at approximately a constant MLT (see Figure 10). The left panel in Figure 12, showing the orbit at 0800 UT, gives a somewhat similar gradient in the 540 to $600 \mathrm{~km}$ altitude range to that expected; however the second orbit at 2000 UT gives quite a different density gradient. The possibility of error is even greater near the F2 peak where the gradients are changing rapidly in going from below to above the peak, resulting in the apparent scale height change at $450 \mathrm{~km}$ seen in the 0800 plot. As a consequence, it is extremely difficult to obtain valid altitude information in the polar ionosphere from a satellite in an elliptical orbit because of the large latitudinal gradients and pronounced UT effects.

\section{Summary}

We combined a simple plasma convection model with an ionospheric-atmospheric density model in order to study the ion composition in the high-latitude winter F-region at solar minimum for low magnetic activity. The details of our timedependent ionospheric-atmospheric density model, including ion chemistry and transport equations, are given by Schunk and Raitt (1980), while the details concerning the combined plasma convection and atmospheric-ionospheric models are given by Sojka et al. (1980c). In a model calculation a field tube of plasma is followed as it moves along a convection trajectory through a moving neutral atmosphere. Altitude profiles of the ion densities are obtained by solving the appropriate continuity, momentum, and energy equations including numerous highlatitude processes. The result of following many field tubes of plasma is a time-dependent, 3-dimensional ion density distribution for each of the ions $\mathrm{NO}^{+}, \mathrm{O}_{2}{ }^{+}, \mathrm{N}_{2}^{+}, \mathrm{O}^{+}, \mathrm{N}^{+}$, and $\mathrm{He}^{+}$. The high-latitude ionosphere above $54^{\circ} \mathrm{N}$ magnetic latitude and at
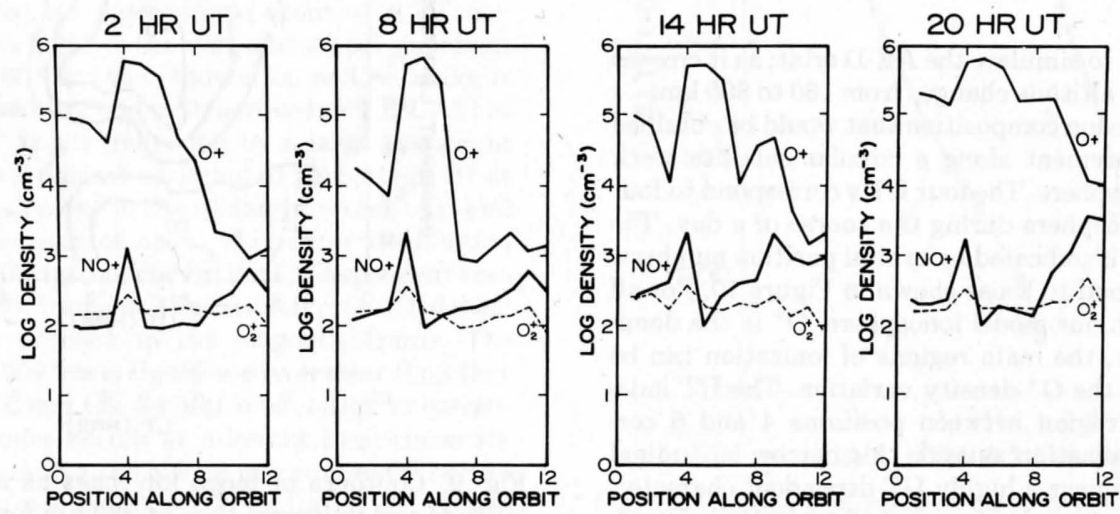

Fig. 11. Calculated ion densities along the circular orbit for four universal times. The positions along the orbit correspond to those shown in Figure 10. 

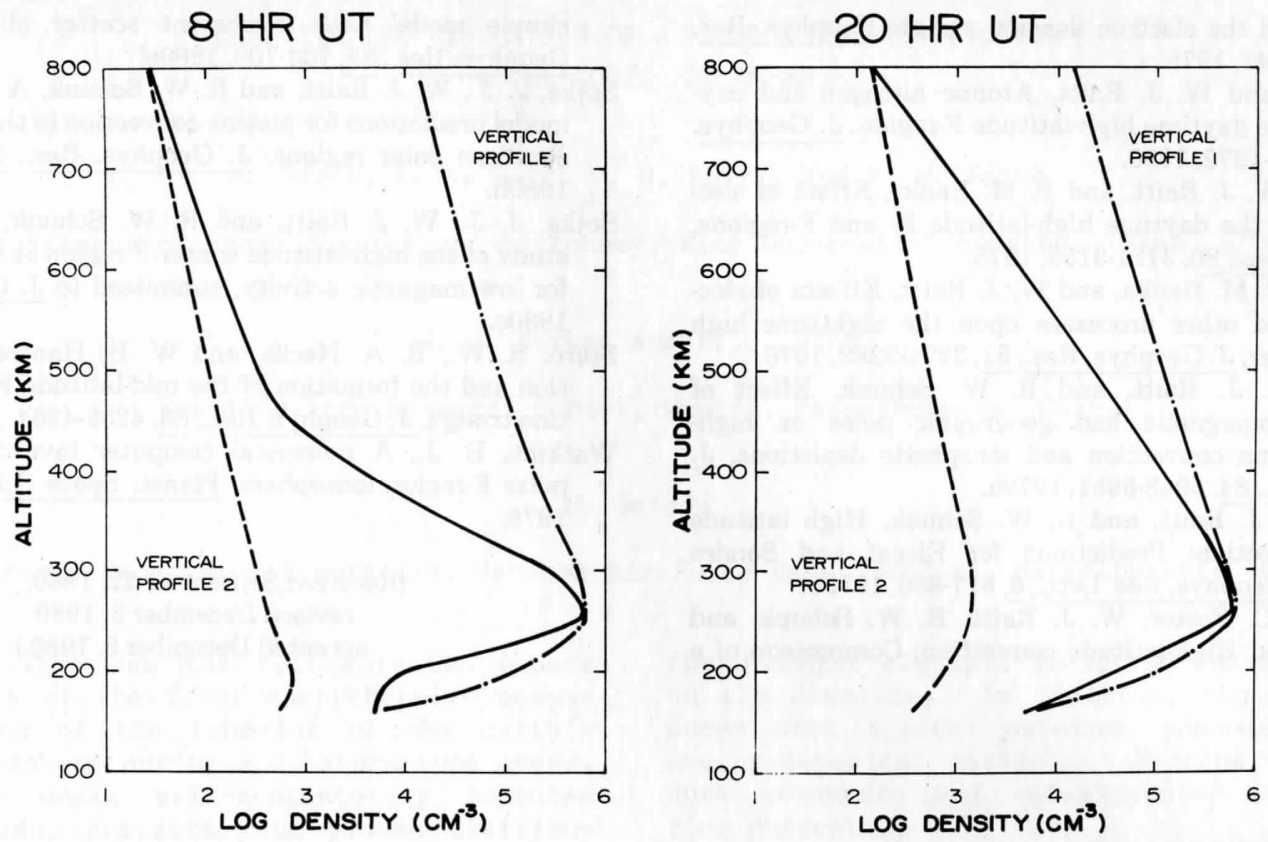

Fig. 12. Calculated electron density variations (solid curves) along the elliptical satellite orbit for two universal times. For each UT, the vertical profile at the two ends of the orbital track are shown by broken curves; the dashed curves are the vertical profiles at point 12 in Figure 10, while the dotted-dashed curves are the vertical profiles at point 4.

altitudes between 160 and $800 \mathrm{~km}$ was covered for 1 complete day.

From our study we found the following.

1. The ion composition exhibits a significant variation with latitude, local time, altitude, and universal time.

2. The variations of the ion composition with latitude and local time are in very good agreement with the $\mathrm{AE}$ measurements presented by Brinton et al. (1978). Table 1 summarizes the regions in the polar ionosphere at $300 \mathrm{~km}$ where either $\mathrm{NO}^{+}$or $\mathrm{O}_{2}^{+}$is the dominant molecular ion, as predicted by our model and as measured by Brinton et al. (1978). There is agreement in five of the six regions; the one exception is the morning sector mid-latitude trough (region 3). Agreement between measurement and theory can be obtained in this latter region if neutral wind effects are included in the model calculations.

3. The predicted $\mathrm{NO}^{+}, \mathrm{O}_{2}{ }^{+}$, and $\mathrm{O}^{+}$densities at $300 \mathrm{~km}$ are in good quantitative agreement with those measured by Brinton et al. (1978).

4. At times and at certain locations, the molecular ion density can be comparable to the $\mathrm{O}^{+}$density at an altitude as high as $300 \mathrm{~km}$ for low geomagnetic activity conditions and hence for small convection electric field strengths. For high geomagnetic activity the importance of the molecular ions should increase.

5. At times and at certain locations, the $\mathrm{O}^{+}$density can be comparable to the molecular ion density at an altitude as low as $200 \mathrm{~km}$.

6. The results listed in result 4 and result 5 have an important implication for the interpretation of incoherent scatter radar spectra, because the spectra are generally interpreted with an assumed ion composition.

7. Ground-based observation sites, such as Chatanika, Millstone Hill, EISCAT, and Sondre Stromfjord, should measure different diurnal variations in ion composition owing in part to the UT response of the high-latitude ionosphere.

8. A satellite in a $300 \mathrm{~km}$ circular polar orbit should measure large orbit to orbit variations in both electron density and ion composition owing to the UT response of the polar ionosphere. An order of magnitude change in electron density can occur on successive orbits, and the minor molecular ions can change from $\mathrm{NO}^{+}$to $\mathrm{O}_{2}{ }^{+}$dominance.

9. It is extremely difficult to obtain valid altitude information in the polar ionosphere from a satellite in an elliptical orbit. For a given orbit, such as an AE-D orbit, the ion density variations with latitude and altitude are comparable, and erroneous conclusions can be drawn about ion density scale heights if the variations along the satellite track are assumed to be only due to altitude variations. Also, information from successive orbits cannot be used to construct altitude profiles of ion density because of the UT variation of the polar ionosphere.

Acknowledgments. This research was supported by Air Force contract USAF/ESD F19628-79-C-0025, NASA grant NAGW-77 and NSF grant ATM80-15497 to Utah State University. The computer modeling effort was supported by the National Center for Atmospheric Research, which is sponsored by the National Science Foundation.

The Editor thanks R. G. Roble for his assistance in evaluating this paper.

\section{References}

Banks, P. M., R. W. Schunk, and W. J. Raitt, $\mathrm{NO}^{+}$and $\mathrm{O}^{+}$in the high latitude F-region, Geophys. Res. Letters, 1, 239-242, 1974.

Brinton, H. C., J. M. Grebowsky, and L. H. Brace, The highlatitude winter F-region at $300 \mathrm{~km}$ : Thermal plasma observations from AE-C, J. Geophys. Res., 83, 4767-4776, 1978.

Knudsen, W. C., Magnetospheric convection and the highlatitude F2 ionosphere, J. Geophys. Res., 79, 1046-1055, 1974.

Knudsen, W. C., P. M. Banks, J. D. Winningham, and D. M. Klumpar, Numerical model of the convecting $\mathrm{F}_{2}$ ionosphere at high latitudes, J. Geophys. Res., 82, 4784, 1977.

Murphy, J. A., G. J. Bailey, and R. J. Moffett, Calculated daily variations of $\mathrm{O}^{+}$and $\mathrm{H}^{+}$at mid-latitudes, J. Atmos. Terr. Phys., 38, 351-364, 1976.

Schunk, R. W., and P. M. Banks, Auroral $\mathrm{N}_{2}$ vibrational 
excitation and the electron density trough, Geophys. Res. Lett., 2, 239-242, 1975.

Schunk, R. W., and W. J. Raitt, Atomic nitrogen and oxygen ions in the daytime high-latitude F-region, J. Geophys. Res., 85, 1255-1272, 1980.

Schunk, R. W., W. J. Raitt, and P. M. Banks, Effect of electric fields on the daytime high-latitude E- and F-regions, J. Geophys. Res., 80, 3121-3130, 1975.

Schunk, R. W., P. M. Banks, and W. J. Raitt, Effects of electric fields and other processes upon the nighttime high latitude F-layer, J. Geophys. Res., 81, 3271-3282, 1976.

Sojka, J. J., W. J. Raitt, and R. W. Schunk, Effect of displaced geomagnetic and geographic poles on highlatitude plasma convection and ionspheric depletions, $\mathrm{J}$. Geophys. Res., 84, 5943-5951, 1979a.

Sojka, J. J., W. J. Raitt, and R. W. Schunk, High latitude plasma convection: Predictions for Eiscat and Sondre Stromfjord, Geophys. Res. Lett., 6, 877-880, 1979b.

Sojka, J. J., J. C. Foster, W. J. Raitt, R. W. Schunk, and J. R. Doupnik, High-latitude convection: Comparison of a simple model with incoherent scatter observations, J. Geophys. Res., 85, 703-709, 1980a.

Sojka, J. J., W. J. Raitt, and R. W. Schunk, A comparison of model predictions for plasma convection in the northern and southern polar regions, J. Geophys. Res., 85, 1762-1768, $1980 b$.

Sojka, J. J., W. J. Raitt, and R. W. Schunk, A theoretical study of the high-latitude winter F-region at solar minimum for low magnetic activity, submitted to J. Geophys. Res., 1980c.

Spiro, R. W., R. A. Heelis, and W. B. Hanson, Ion convection and the formation of the mid-latitude F-region ionization trough, J. Geophys. Res., 83, 4255-4264, 1978.

Watkins, B. J., A numerical computer investigation of the polar F-region ionosphere, Planet. Space Sci., 26, 559-569, 1978.

(Received September 22, 1980; revised December 5, 1980; accepted December 8, 1980.) 